\title{
National Program of Cancer Registries
}

National Cancer Institute

\section{Source}

National Cancer Institute. National Program of Cancer Registries. NCI Thesaurus. Code C141462.

Established by Congress through the Cancer Registries Amendment Act in 1992, and administered by CDC, the National Program of Cancer Registries (NPCR) collects data on cancer occurrence (including the type, extent, and location of the cancer), the type of initial treatment, and outcomes. It supports central cancer reg istries in 46 states, the District of Columbia, Puerto Rico, the U.S. Pacific Island Jurisdictions, and the U.S. Virg in Islands. 